\title{
GENERALIDADE E PARTICULARIDADE NA SOCIOLOGIA BRASILEIRA
}

\section{Otávio Soares Dulci}

Resumo. A sociologia é uma ciência que procura estabelecer proposições gerais sobre fenômenos sociais, mas suas investigações se desenvolveram, desde a origem, a partir de diferentes tradições nacionais, dirigindo-se a problemas específicos. O artigo examina a formação da sociologia brasileira como processo intelectual marcado pela percepção de possíveis peculiaridades da sociedade brasileira diante de modelos gerais de cunho determinista. Argumenta que, ao enfrentar esse dilema, a sociologia brasileira tem oferecido contribuição importante ao conhecimento genérico da vida social na medida em que, com os seus estudos, a experiência do Brasil pode ser situada em termos comparativos. Essa proposição é ilustrada por uma recapitulação do debate sobre a questão racial na fase clássica da ciência social brasileira - de fins do século XIX ao meio do século XX.

Palavras-chave: Ciência social, sociologia brasileira, generalidade, particularidade, teoria.

Otávio Soares Dulci é professor de Sociologia da Universidade Federal de Minas Gerais. Sociólogo e Mestre em Ciência Política pela UFMG. Doutor em Ciência Política pelo IUPERJ, com estudos de pós-graduação na Universidade de Glasgow, Grã-Bretanha. Autor dos livros A UDN e o Anti-Populismo no Brasil (Ed. UFMG, 1986) e Política e Recuperação Econômica em Minas Gerais (Ed. UFMG, 1997), de capítulos de livros em várias coletâneas, bem como de diversos artigos nos campos da sociologia e da política brasileira moderna. 
Uma das questões de interesse no estudo do pensamento social brasileiro diz respeito à possível especificidade da produção sociológica elaborada no país ao longo do tempo. Em que medida esse acervo constitui uma sociologia propriamente brasileira? Nesta pergunta, a ênfase no adjetivo chama a atenção para o que haveria de singular no empreendimento, de acordo com vários critérios (os temas, os enfoques, os resultados, etc.). Ou, ao invés, tratar-se-ia de uma sociologia tout court, apenas feita no Brasil, que, por suposto, possuiria sentido eminentemente generalizante?

Este é um assunto relevante sob vários aspectos. Examino-o aqui em três partes. Primeiro, procuro situar alguns problemas analíticos envolvidos na caracterização da sociologia como disciplina de âmbito universal que é ao mesmo tempo produzida em contextos nacionais. Em segundo lugar, transponho essa discussão para o Brasil, por meio da releitura de uma controvérsia surgida na década de 50 a respeito desse tema. $\mathrm{Na}$ terceira parte, procuro identificar, na fase clássica do pensamento social do Brasil, de que forma a tensão entre conhecimento genérico e específico se expressou em contribuições apreciáveis à investigação sociológica.

\section{I}

A questão de uma sociologia brasileira suscita, para começar, o antigo debate sobre a caracterização das ciências sociais como nomotéticas ou idiográficas. O modelo nomotético de ciência orienta a investigação para o estabelecimento de proposições gerais sobre fenômenos, com vistas a alcançar eventualmente um conjunto sistemático de leis. $\mathrm{O}$ modelo idiográfico, por sua vez, tem como alvo a descrição ou interpretação de fenômenos singulares no espaço e no tempo; seus praticantes se concentram na realidade empírica, descartando a meta de construção teórica cumulativa.

Deve a sociologia se orientar para proposições gerais sobre fenômenos sociais? É provável que, em tese, haja amplo acordo sobre o caráter nomotético da disciplina, tal como nos ensinam os manuais. Mas não é assim na prática, uma vez que grande parte dos trabalhos sociológicos é de cunho monográfico. Ocorre com a sociologia o mesmo que Panebianco (1994, p. 82-83) apontou a respeito da ciência política, 
cujos estudos tratam, comumente, de objetos tidos como importantes ou interessantes em si mesmos, não pela contribuição que sua análise possa dar à construção ou à refutação de teorias científicas. Daí a proliferação de especialistas em países, no estilo dos brazilianists.

Como isso acontece em toda parte, podemos atribuí-lo a diversos fatores. Entre eles se destacam, naturalmente, os que se relacionam à formação dos cientistas sociais e às modalidades de trabalho predominantes em seu meio. Os sociólogos, com freqüência, são chamados a atuar como sociógrafos: focalizam questões localizadas em busca de diagnósticos e soluções práticas. Mas igualmente importante é a influência de fatores contextuais (sociais, culturais, históricos) nos rumos seguidos pela sociologia nas diversas comunidades nacionais de cientistas e profissionais. Esse seria outro aspecto decisivo que o nosso problema inicial sugere. Diz respeito à sociologia do conhecimento, vertente que aborda os condicionamentos históricos e sociais da construção do pensamento.

Há, ainda, um terceiro nível de considerações, referente às finalidades pragmáticas do trabalho científico, que no caso da sociologia adquire imediato destaque em virtude do próprio objeto da disciplina. O nexo entre o avanço do conhecimento sociológico e a sua utilidade para a implementação de projetos nacionais (a superação do subdesenvolvimento, por exemplo) marcou, por muito tempo, a trajetória das ciências sociais não só no Brasil como em todo o Terceiro Mundo.

Por certo, esse tipo de conexão é bem mais geral, tal como sucede com o impacto de condições históricas e sociais sobre a elaboração científica. A construção da sociologia em termos globais derivou de esforços de indivíduos e de grupos que costumam ser identificados por sua raiz nacional e, mais ainda, pelo envolvimento com questões de seu tempo. Assim é que, ao estudarmos as origens e a evolução deste campo do conhecimento, deparamo-nos com o contraste entre a sociologia francesa, a alemã e a norte-americana, para citar as mais influentes. E cada uma delas se constituiu com fisionomia própria, fruto de uma dada história intelectual, de um ambiente cultural específico e de uma agenda de questões sociais concretas. A sociologia francesa emergiu, com Durkheim e seus sucessores, na esteira do Iluminismo e do Positivismo comteano. Por sua vez, a sociologia norteamericana avançou sob o estímulo das mudanças sociais do país no 
início do século XX, bem visível na criatividade temática e metodológica da Escola de Chicago.

Com isso, não se quer dizer que esses esforços se limitaram a uma perspectiva paroquial. Ao contrário, dirigiam-se a problemas analíticos surgidos de contextos específicos, mas com a intenção de situá-los em termos universais. Aliás, uma crítica que se faz aos clássicos é a de sua excessiva propensão ao determinismo, sobretudo no estudo da mudança social, no afã de estabelecer tipos gerais e causas "últimas" dos processos que investigavam (Etzioni e Etzioni, 1964: cap. 1). Com o tempo, a sociologia reduziu o seu foco, mas adotando a tendência oposta de renunciar a qualquer perspectiva macro-histórica (Moore, 1972: cap. 4). Esse deslocamento terá concorrido para a difusão do modelo idiográfico, não só pelo abandono da visão histórica (ou seja, da análise de relações sociais em processo), como, paralelamente, pelo desinteresse em efetuar comparações, no tempo e no espaço.

Observa-se, porém, em fase recente, renovado interesse pelo método comparativo, fomentado em especial pelos estudos que compõem o campo da sociologia histórica. Não obstante a variedade de enfoques dos autores classificados sob este rótulo ${ }^{1}$, seus trabalhos abrem caminho para a superação das dificuldades apontadas. O propósito eminentemente comparativo, portanto generalizante, distingue-os da mera sociografia de casos isolados. Mas, ao pesquisarem trajetórias e tipos de desenvolvimento, afastam-se da posição determinista que supõe o processo histórico como não-problemático e encara as diferenças entre sociedades como correspondendo a etapas de um caminho essencialmente homogêneo para certo futuro postulado em teoria.

A retificação dessa idéia de um futuro já dado, dessa noção fechada da história humana que não admite surpresas, será um avanço significativo para a análise sociológica, caso prevaleça sobre as proposições evolucionistas (como a fórmula recente do "fim da história") recorrentes no campo das ciências sociais. O avanço se traduz na busca de generalizações que sejam capazes de contemplar os processos sociais tanto em sua dimensão universal quanto naquilo que têm de particular. Como escreveu Bendix (1968, p. 76):

Os estudos sociológicos comparativos representam uma tentativa de desenvolver conceitos e generalizações em um nível intermediário 
entre o que é verdadeiro para todas as sociedades e o que é verdadeiro para uma sociedade em um ponto no tempo e no espaço.

Nesse sentido é que a influência cognitiva dos contextos adquire grande importância. O contexto cultural, por exemplo, tem sido destacado para relativizar o postulado da universalidade das categorias de análise, bem como a noção da universalidade das práticas sociais e políticas (Badie e Hermet, 1990: cap. 1). É um aporte necessário, mas que traz consigo certos riscos. No limite, se tudo é relativo, as ciências sociais serão paralisadas pela profusão de explicações ad hoc, de alcance apenas local.

Todos esses elementos são importantes para esclarecer em que termos se pode falar de uma sociologia brasileira. Vejamos, em seguida, como essa questão foi levantada e respondida no Brasil.

\section{II}

A discussão sobre o caráter da sociologia no Brasil veio à tona pela primeira vez em meados da década de 50. Foi nessa época que surgiram as primeiras reflexões sistemáticas sobre a evolução do pensamento social brasileiro, acompanhadas de tentativas de classificação de suas fases e de suas principais perspectivas de análise. Tais reflexões se devem a Guerreiro Ramos e a Florestan Fernandes, dois autores de grande envergadura no panorama da disciplina e que mantinham posições divergentes acerca do problema de que nos ocupamos. ${ }^{2}$

Guerreiro Ramos se notabilizou pelo esforço de fundamentar o projeto de uma sociologia nacional. Não assumia propriamente uma visão idiográfica, pois reconhecia que "o ideal dos sociólogos é a sociologia "universal", livre de condicionamentos históricos e de compromissos nacionais, "aproximada, quanto ao grau de abstração, da física ou da matemática" (Ramos, 1953, p.7). Mas salientava que nem estas últimas, nem muito menos a sociologia, se eximem de contingências de espaço e de tempo: ainda que se mantenha o ideal universal da ciência, as sociologias (no plural) "têm sido instrumentos de decifração nacional, mesmo nos seus aspectos aparentemente mais abstratos. Seus conceitos são historicamente condicionados." E suas formulações teóricas, "permeadas de influências nacionais", são 
"caudatárias de tradições militantes, orientadas no sentido pragmático" (Ramos, 1953, p. 8-9).

É sob essa perspectiva que Guerreiro Ramos abordou o cenário sociológico brasileiro de seu tempo. Crítico veemente da produção acadêmica, que lhe parecia presa a modelos importados e desligada da realidade circundante - uma sociologia enlatada, "consumida como uma verdadeira conserva cultural" - defendeu ao invés uma sociologia 'em mangas de camisa', instrumento de autoconhecimento e de autonomia nacional:

A essência de toda sociologia autêntica é, direta ou indiretamente, um propósito salvador e de reconstrução social. Por isso, inspirase numa experiência comunitária vivida pelo sociólogo, em função da qual adquire sentido. Desvinculada de uma realidade humana efetiva, a sociologia é uma atividade lúdica da mesma natureza do pif-paf. (...) Daí, na medida em que o sociólogo exercita vitalmente a sua disciplina, é forçosamente levado a entrelaçar o seu pensamento com a sua circunstância nacional ou regional. (Ramos, 1995, p. 107)

Analogamente, sua interpretação da trajetória do pensamento social no Brasil gira em torno do contraste entre duas correntes de idéias, que, para ele, caracterizam países de origem colonial:

a) uma delas "consiste simplesmente numa glosa das orientações doutrinárias vigentes nos centros de cultura estrangeiros";

b) outra é "orientada no sentido da dessatelização histórica,(cujos) epígonos são verdadeiramente criadores e se caracterizam por uma tendência política mais do que propriamente especulativa" (Ramos, 1953, p. 10-11).

Esta dicotomia traduziria, para Guerreiro Ramos, a diferença entre uma sociologia brasileira e uma sociologia apenas feita no Brasil.

Florestan Fernandes, por sua vez, tende a pensar a relação entre a atividade científica e o seu contexto menos como um dado e mais como um problema a ser equacionado. Para ele, é "legítima e necessária" a visão do cientista "como participante de um cosmos cultural autônomo, o qual possui normas e valores próprios, capazes de promover a ordenação das diferentes atividades intelectuais de cunho científico" (Fernandes, 1958, p. 15). Sob esse ângulo, o caráter 
universal, unitário, da ciência deriva diretamente de sua institucionalização, não das comunidades a que serve. É a dinâmica interna da atividade que provoca, de modo convergente, o avanço do conhecimento e de suas aplicações, a despeito de todas as diferenças que possam existir entre os cientistas em assuntos extracientíficos.

Porém, acrescenta, não se pode ignorar "que as condições sociais ambientes exercem uma influência ativa e contínua na organização e no funcionamento das instituições científicas, bem como na formação do horizonte intelectual do cientista" (Fernandes, 1958, p. 16).

Ambas as implicações são relevantes. A primeira tem a ver com os condicionamentos econômicos e socioculturais a que se sujeita $o$ desenvolvimento institucional da ciência. A segunda, com a influência de outros sistemas de normas e valores sobre as escolhas dos cientistas, escolhas pretensamente neutras, mas que ocultam inspirações filosóficas, políticas e ideológicas.

Assim, tanto a seleção dos objetos de investigação quanto o grau de elaboração teórica dos dados e principalmente o destino dos resultados são estreitamente influenciados pelo meio social. Mas Florestan Fernandes enfatiza "o equilíbrio que precisa existir, no mundo da ciência, entre os móveis positivos e os móveis extra-científicos das investigações" (Fernandes, 1958, p. 23). Pode-se dizer que, para ele, a articulação do cientista com o meio se exprime no antes e no depois. O durante, a pesquisa, deve estar livre de injunções externas.

É recorrente na obra de Florestan Fernandes a discussão de contingências de tipo institucional e cultural sobre o progresso da sociologia. Mas preocupa-o também a influência do ambiente sobre a formação do "horizonte intelectual do sociólogo brasileiro". Tal influência, segundo pensa, pode ser altamente construtiva. No entanto, tende a comprometer o equilíbrio preconizado, quando se adotam duas atitudes extremas: a de ignorar o contexto, que leva a uma sociologia puramente especulativa, sem ancoragem empírica; ou a de ceder aos influxos do meio social, redundando numa espécie de sociografia. As idéias de Guerreiro Ramos, a seu ver, conduziriam a este último resultado (Fernandes, 1958, p. 23-24).

Dadas essas premissas, a análise de Fernandes sobre o desenvolvimento da sociologia no Brasil é pautada por critérios bem diversos dos adotados por Ramos. No estudo mais sistemático que dedicou ao 
tema, Fernandes (1977) aborda a questão prévia dos obstáculos culturais que impediram, até certa época, a aceitação da sociologia no país, assim como os processos sociais que levaram a superar tais obstáculos. Interessa-se, sobretudo, pela constituição de padrões de trabalho científico ao longo do tempo, relacionando-a com fatores estruturais, políticos e culturais. De início, a sociologia foi explorada no Brasil como recurso secundário de interpretação (por autores que deram atenção a fatores sociais para esclarecer certos problemas intelectuais ou práticos). Já em meados do século XX, era possível observar "a preocupação dominante de subordinar o labor intelectual, no estudo dos fenômenos sociais, aos padrões de trabalho científico sistemático" (Fernandes, 1977, p. 28).

É uma evolução tardia em relação à sociologia européia. Mas, para o autor, há vantagens nesse atraso,

que oferece um ponto de partida mais rico ao jovem sociólogo brasileiro ou que lhe concede uma posição ideal para realizar uma síntese neutra entre os resultados e as tendências metodológicas da sociologia em países europeus e nos Estados Unidos. (Fernandes, 1977, p. 28)

Essa sugestão aponta para a construção de uma sociologia brasileira nos termos em que essa expressão condiz com a visão de Florestan Fernandes. Trata-se, para os sociólogos brasileiros, de combinar em sua atividade a busca de dois objetivos: o de contribuir para o progresso da sociologia como ciência e o de contribuir para o conhecimento sociológico do Brasil. O resultado dessa orientação é uma sociologia que, ao investigar a realidade próxima, o faz sobre um alicerce teórico que lhe permite alcançar relevância científica mais ampla.

Isso supõe criação e reflexão teórica, em contraste com a aplicação literal de teorias importadas. E aqui temos um nítido ponto de encontro entre os dois autores. De Guerreiro Ramos, a contribuição científica mais sólida, e certamente a mais original, foi a formulação do método de 'redução sociológica' " "procedimento crítico-assimilativo da experiência estrangeira", que se guia "por uma aspiração ao universal mediatizado, porém, pelo local, regional ou nacional" (Ramos, 1958, p. 46). A 'redução' implica reelaboração do que é transplantado de fora, tanto por razões cognitivas quanto por finalidades práticas. 
Pois bem, o ideal de decifração nacional, de autoconhecimento, sobre o qual Ramos tanto insiste, na medida em que requer tal esforço de reelaboração, concorre não só para o conhecimento científico do país, mas também para o avanço da sociologia como ciência, realizando assim o duplo objetivo proposto por Fernandes aos sociólogos brasileiros. A estes se abrem oportunidades de contribuir para o saber sociológico exatamente pelo estudo do que o Brasil apresenta de singular. Aí se encontra um grande manancial de reflexão teórica, capaz de influenciar os rumos da disciplina.

\section{III}

Há alguns anos, li um comentário interessante de Mariza Corrêa sobre a antropologia brasileira. Esta, dizia a autora, dirigiu precocemente seu foco para questões, como o hibridismo e o sincretismo, que com o tempo passaram a ser devidamente valorizadas em países que se vêem às voltas com a penetração cada vez maior de estrangeiros:

temas, ou noções, tradicionalmente discutidos aqui como parte de nossa tradição (disciplinar, antropológica) nacional, agora são uma preocupação internacional, parte das questões do tema da globalização. (Corrêa, 1997, p. 12)

É uma observação que se aplica também à sociologia. De fato, a sociologia construiu no Brasil uma tradição própria, ao buscar respostas para as questões que se lhe apresentavam a partir da realidade social do país. E ao fazê-lo, demonstrou notável capacidade de contribuir para o conhecimento sociológico (em sentido nomotético) precisamente pela investigação do que o Brasil oferecia de singular.

Isso decorreu da interpelação de modelos teóricos de alcance pretensamente universal que pareciam inconsistentes com os dados da realidade brasileira. Proposições alternativas foram então elaboradas para dar conta dessa realidade. Embora seus autores quase sempre tratassem do Brasil em si, abriram, explícita ou implicitamente, perspectivas de análise comparativa que permitiam situar o caso brasileiro em face de casos equivalentes ou contrastantes. Classificações novas, levando a percepções mais complexas, menos 
redutoras, de temas relevantes da sociologia, resultaram desses esforços de análise das peculiaridades da experiência brasileira.

Podemos identificar esse tipo de contribuição nos campos mais expressivos do itinerário do pensamento social no Brasil: a análise da questão racial, a abordagem sociológica da política e a discussão da temática do desenvolvimento. Utilizarei a primeira para ilustrar o argumento.

A composição multirracial do Brasil, suas implicações e seus dilemas, constituem o objeto mais característico da investigação social brasileira, a julgar pelo fato de ter mobilizado a atenção de quase todos os autores ao longo da formação da disciplina em nosso país, ou seja, do final do século XIX aos meados do século XX. Desde os precursores, como Joaquim Nabuco, às voltas com o impacto sistêmico da escravidão, até os modernos, como Florestan Fernandes, Fernando Henrique Cardoso e Octavio Ianni, interessados na dinâmica da desigualdade racial em conexão com o avanço capitalista, foi recorrente a preocupação com o tema, ensejando enfoques bastante distintos.

Os enfoques foram distintos, mas percebe-se um certo padrão evolutivo no modo de tratar a matéria, que ilustra claramente o aproveitamento do potencial analítico proporcionado pelo estudo do Brasil para o avanço do conhecimento sociológico.

A perspectiva originária sob a qual o quadro racial brasileiro foi encarado era francamente determinista, orientada pelas teorias de hierarquia racial prevalecentes na Europa e na América do Norte. A expressão mais coerente dessa posição encontra-se na obra de Nina Rodrigues, exemplar pela fidelidade ao cânone nomotético. Sem deixar de reconhecer o alto valor de seu legado científico, no que diz respeito ao estudo da população afro-brasileira, impressionam aos leitores de hoje os juízos implacáveis de Nina Rodrigues sobre os mestiços de Canudos em As Coletividades Anormais, fruto do crédito que dava ao dogma do determinismo biológico.

O racismo científico, somando-se ao prestígio das teorias de determinismo geográfico, produziu uma leitura profundamente pessimista sobre o país. Sociedade multirracial, com alto índice de miscigenação, situada nos trópicos, segundo essa leitura o Brasil não possuía nenhuma das condições "naturais" para alcançar o nível das nações genuinamente civilizadas. 
No entanto, o mimetismo dos intelectuais brasileiros não os impediu de vislumbrar uma saída para tais obstáculos ao progresso. Essa saída consistiu na teoria do branqueamento. Projetava-se para o início do século XXI a transformação do Brasil em uma nação quase totalmente branca por efeito de dois fatores: a imigração intensiva de europeus e o incremento da mistura entre brancos, negros e índios, redundando na extinção gradual dos dois últimos grupos por sua suposta inferioridade. Nesse sentido contornavam-se os rígidos princípios do racismo científico para adaptá-lo às contingências de um país acentuadamente mestiço. As teorias estrangeiras eram assim copiadas, mas de forma original, como notou Schwarcz (1993) em análise atraente da questão. A tese do branqueamento era uma heresia à luz da ciência predominante nas primeiras décadas do século XX, a qual encarava a mistura de raças como fator de degeneração não só biológica como cultural. E é essa característica desviante que chama a atenção, tivesse ou não fundamento a expectativa de se transformar gradualmente o Brasil em um país de brancos, idéia que, afinal, tornouse importante referencial ideológico desde então.

Além disso, a aplicação da ortodoxia à realidade provocava resultados inesperados, como se verifica em Os Sertões. Euclides da Cunha, engenheiro de extração positivista, organizou seu estudo de acordo com os estritos cânones da ciência da época. Desenvolveu, em seqüência, uma descrição do meio físico (“A Terra”), uma caracterização do habitante do sertão inspirada na antropologia racial ("O Homem") e finalmente uma extensa narrativa da história do movimento de Canudos e de seu extermínio ("A Luta"). Ao relatar os fatos, as teorias que tomava como base para postular a inferioridade racial, cultural, moral - dos rebelados são contraditadas pelo próprio autor, que não disfarça a admiração pela sua bravura e conclui com uma vigorosa denúncia do genocídio provocado pelas autoridades brancas, educadas, "civilizadas".

O conteúdo contraditório de Os Sertões anunciava uma mudança de paradigma, pondo em causa a antinomia civilização versus barbárie vinculada ao pensamento racista vigente. Outra obra, também do início do século XX, representou uma investida mais articulada contra as idéias reinantes, embora por isso tenha permanecido em relativa obscuridade. Trata-se de América Latina: Males de Origem, de Manoel Bomfim. Seu foco é a América Latina, o que era novidade no 
Brasil, e lhe confere grande valor como esboço de análise comparativa. Seu objeto, o atraso do continente, que debita à mentalidade parasitária dos colonizadores ibéricos. O ataque ao tipo predatório de colonização é forte, mas não menos contundente é o questionamento da ciência eurocêntrica da época, que incutia nos latino-americanos um sentimento perene de inferioridade por causa de sua origem étnica e de suas carências econômicas e educacionais. Sob o ângulo que aqui nos interessa, Bomfim é um autor-chave, ao deslocar a explicação do atraso para fatores históricos, portanto mutáveis, em vez de fatores naturais (a composição racial, o meio geográfico). Por esse deslocamento, e pela preocupação de abordar o Brasil em paralelo aos países vizinhos, o estudo de Bomfim é um empreendimento pioneiro de sociologia histórica. Recusa os esquemas teóricos deterministas de seu tempo, mas apenas para substituí-los por uma análise alternativa de cunho também genérico, aplicável a todos os países de origem colonial.

O modelo ibérico de colonização, alvo da crítica de Bomfim, seria mais tarde revalorizado por Gilberto Freyre como elemento fundamental de sua investigação do sistema de relações raciais que se constituiu no Brasil. Freyre, em seus primeiros livros, que são também os principais de sua vasta obra, estudou o Nordeste açucareiro numa perspectiva sócio-histórica. Mas o alcance de sua proposta foi muito mais amplo, na medida em que concorreu para desmontar a crença nas idéias deterministas que persistiam como explicações do atraso do Brasil. Ou seja, as idéias relativas à composição multirracial, aos males da miscigenação e à localização tropical, cujas implicações negativas obviamente se estendiam para todos os outros países com tais características. O giro teórico de Freyre, ao inverter o sentido desses atributos, ressaltando-lhes as qualidades civilizatórias, representou uma notável contribuição da ciência social brasileira ao avanço do conhecimento global nesse domínio do saber.

É tarefa complexa avaliar o mérito da obra de Freyre, o que permanece dela e o que foi retificado por investigações posteriores. Com o foco dirigido para a vida privada, Freyre tendia a ignorar o arcabouço estrutural dos fenômenos que estudava. Para muitos críticos, suas análises têm um acento conservador e até reacionário, devido à sua idealização do passado. A visão conciliatória que transmitiu das relações interétnicas no sistema escravista consolidou a imagem do 
Brasil como democracia racial - uma noção de senso comum derivada de comparação com sociedades multirraciais conflitivas como os Estados Unidos e a África do Sul.

Mito ou realidade? É freqüente considerar-se a noção de democracia racial sugerida pela obra de Freyre como uma categoria meramente ideológica, mas para a sociologia interessa igualmente tratála como problema analítico. A caracterização do modelo ibérico de colonização (redundando na noção de 'lusotropicalismo'), sobretudo quanto às suas implicações para as relações interétnicas, é um tema substancioso do legado de Freyre que permanece na agenda científica em escala internacional. Sua abordagem da experiência brasileira pelo ângulo da sociologia histórica possui relevância análoga à de Bomfim, ainda que as duas estejam em pólos opostos no tocante às respectivas leituras do processo.

E mesmo para o estudo das relações raciais contemporâneas, o recurso às hipóteses de Freyre pode ser proveitoso. Com base em pesquisa realizada na área metropolitana de Salvador sobre o quotidiano das relações raciais no contexto da globalização, Sansone (1996) reexamina à luz dos dados de hoje a descrição de Freyre sobre o habitus racial do passado - o conjunto de regras de relações raciais sobre as quais existe um certo e problemático consenso. Chega à conclusão de que "uma parte do quadro das relações raciais fornecido por Freyre e a apresentação de alguns dos dilemas embutidos nestas relações continuam atuais" (Sansone, 1996, p. 209). Especificamente no que tange ao habitus racial, caracterizado pela hibridez, plasticidade e adaptabilidade.

A mitificação do Brasil como democracia racial motivou a UNESCO a patrocinar estudos que investigassem essa questão nos primeiros anos da década de 50 . O retrato resultante dos dados não confirmou o mito. Esse projeto foi importante, entre outras razões, por iluminar a persistência das desigualdades raciais no bojo da modernização urbano-industrial em curso no país. Na Bahia, Thales de Azevedo identificou a simbiose entre duas hierarquias, a de classe e a de status, esta associada à cor e à origem racial, num contexto social já distante da antiga ordem escravista (Guimarães, 1996). Em São Paulo a pesquisa esteve a cargo de Roger Bastide e Florestan Fernandes, sendo este último quem explorou mais largamente o tema 
em várias de suas obras. Ali também foi observada a persistência da hierarquia racial em contraponto ao desenvolvimento da sociedade de classes. A interpretação de Fernandes (1965) enfatiza o efeito de retardamento que a persistência da discriminação racial exerce sobre o desenvolvimento da ordem capitalista. Interessa-se sobretudo pela dinâmica da situação, no pressuposto teórico de que o desenvolvimento da sociedade de classes, ou da ordem competitiva, como prefere, implica a dissolução gradual das demais formas de desigualdade. Pensa, portanto, em democratização racial como processo, em vez de democracia racial como sistema.

Ambas as análises, a de Thales de Azevedo e a de Florestan Fernandes, convergiram na refutação do mito. Extraíram, no entanto, conclusões diversas de seus achados, e não somente em virtude das diferenças estruturais entre a Bahia e São Paulo. Estabelecia-se naquele momento uma bifurcação analítica que prossegue na sociologia brasileira. A vertente de Azevedo tem sido aprofundada por estudos (por exemplo, Hasembalg, 1979; Hasembalg e Valle Silva, 1988) que demonstram a reprodução contínua das desigualdades baseadas no critério de raça, mais de um século após o término oficial da escravidão.

Seria arriscado, contudo, descartar de todo a proposição de Florestan Fernandes, que alude à equalização de oportunidades e ao avanço da cidadania. De todo modo, foi a partir dessa investigação que ele caminhou para a elaboração de sua teoria do desenvolvimento dependente (Fernandes, 1976). Nesta obra concretizou-se admiravelmente o duplo propósito que o seu autor havia apontado para a sociologia brasileira: ao contribuir para o conhecimento sociológico do Brasil, ofereceu uma contribuição magistral à sociologia como ciência. 


\section{Notas}

1 Para uma apreciação de conjunto, v. Skocpol, 1984. Uma diferença importante entre os autores diz respeito ao grau de pretensão explicativa, variando desde os que utilizam comparações históricas apenas para ilustrar esquemas teóricos (Eisenstadt, por exemplo) até minimalistas como Bendix, que se limitam a interpretar "contrastes de contextos" numa linha weberiana.

2 Para uma visão mais ampla dessa controvérsia, v. a esclarecedora análise de Oliveira (1995).

Abstract. Sociology is a science which seeks to establish general propositions about social phenomena, yet its investigations stemmed, since its origins, from different national traditions, addressing to specific problems. The article examines the formation of Brazilian sociology as an intellectual process marked by the perception of possible peculiarities of the Brazilian society toward general deterministic models. It argues that, in facing this dilemma, Brazilian sociology has offered an important contribution to building generic knowledge of social life insofar as, with its studies, Brazilian experience can be place in comparative terms. Such proposition is illustrated by a brief analysis of the debate on the racial question along the classical period of the Brazilian social science - from the end of XIXth century to the midlle of XXth century.

Résumé. La sociologie est une science qui cherche d'établir des propositions générales sur des phénomènes sociaux, mais ses investigations sont toujours dirigées vers des problèmes spécifiques. Ces investigations sont encore dérivés, dès le début, de différentes traditions nationales. L'article approche la formation de la sociologie brésilienne comme un processus intellectuel signalé par la perception de possibles singularités de la société brésilienne devant des models généraux déterministes. 


\section{Referências Bibliográficas}

BAdie, Bertrand e Hermet, Guy (1990). Politique comparée. Paris: Presses Universitaires de France.

Bendix, Reinhard (1968). "Concepts in comparative historical analysis". In: Rokkan, Stein (ed.). Comparative research across cultures and nations. The Hague: Mouton.

CorrêA, Mariza (1997). In: Jornal da Ciência, XII (380), 5 de dezembro de 1997.

Etzioni, Amitai, Etzioni, Eva, eds. (1964). Social change: sources, patterns and consequences. New York: Basic Books.

FERnANDES, Florestan (1958). O padrão de trabalho científico dos sociólogos brasileiros. Belo Horizonte: Edições da Revista Brasileira de Estudos Políticos.

(1965). A integração do negro na sociedade de classes. São Paulo: Dominus/USP.

(1972). O negro no mundo dos brancos. São Paulo: Difusão Européia do Livro.

(1976). A revolução burguesa no Brasil; ensaio de interpretação sociológica. $2^{\mathrm{a}}$ ed. Rio de Janeiro: Zahar.

(1977). "Desenvolvimento histórico-social da Sociologia no Brasil". In: A Sociologia no Brasil (Contribuição para o estudo de sua formação e desenvolvimento). Petrópolis: Vozes.

Guimarães, Antônio Sérgio (1996). "Cor, classes e status nos estudos de Pierson, Azevedo e Harris na Bahia: 1940-1960”. In: Maio, Marcos Chor e Santos, Ricardo Ventura (orgs.). Raça, Ciência e Sociedade. Rio de Janeiro: Fiocruz/CCCB.

Hasembalg, Carlos A. (1979). Discriminação e desigualdades raciais no Brasil. Rio de Janeiro: Graal.

Hasembalg, Carlos A., Valle Silva, Nelson do (1988). Estrutura social, mobilidade e raça. Rio de Janeiro: Vértice.

Moore, Jr., Barrington (1972). “A estratégia da Ciência Social”. In: Poder político e teoria social. São Paulo: Cultrix. 
Oliveira, Lúcia Lippi de (1995). "O trabalho sociológico: dois padrões". In: A Sociologia do Guerreiro. Rio de Janeiro: Editora UFRJ.

PAnebianco, Angelo (1994). “Comparación y explicación”. In: SARTori, Giovanni, Morlino, Leonardo (eds.). La comparación en las Ciencias Sociales. Madrid: Alianza.

Ramos, Guerreiro (1953). O processo da Sociologia no Brasil (Esquema de uma História de Idéias). Rio de Janeiro. (1958). A redução sociológica (Introdução ao estudo da razão sociológica). Rio de Janeiro: ISEB.

(1995). Introdução crítica à sociologia brasileira. $2^{\mathrm{a}}$ ed. Rio de Janeiro: Editora UFRJ.

SAnsone, Lívio (1996). “As relações raciais em Casa-Grande \& senzala revisitadas à luz do processo de internacionalização e globalização". In: MAIO, Marcos Chor, SANTOS, Ricardo Ventura (orgs.). Raça, Ciência e Sociedade, Rio de Janeiro: Fiocruz/CCCB.

Schwarcz, Lília Moritz (1993). O espetáculo das raças: cientistas, instituições e questão racial no Brasil, 1870-1930. São Paulo: Companhia das Letras.

SkостоL, Theda, ed. (1984). Vision and method in historical sociology. Cambridge: Cambridge University Press. 